\title{
Contratualização de resultados na gestão educacional escolar em redes estaduais de ensino
}

\author{
Contractualization of results in school educational management in state \\ teaching networks
}

Contractualización de resultados en la gestión educativa escolar en redes

estatales de enseñanza

TEISE DE OLIVEIRA GUARANHA GARCIA

Resumo: $\mathrm{O}$ artigo, a partir de levantamento de dados em fontes primárias realizado em pesquisa interinstitucional que estuda estratégias de privatização nas redes estaduais de ensino brasileiras, apresenta e analisa a contratualização da gestão educacional e escolar nos estados brasileiros. Verifica-se que após as experiências pioneiras de Minas Gerais, outros estados introduziram formas de contratualização da gestão, sobretudo a partir da segunda metade dos anos 2000

Palavras-chave: Contratualização, gestão educacional, gestão escolar.

Abstract: The article presents and analyzes the contractualisation of educational and school management in the Brazilian's states, based on data collected from primary sources carried out in interinstitutional research that studies privatization strategies in Brazilian state education networks. It is verified that after the pioneering experiences of Minas Gerais, other states have introduced forms of contract management, especially in recent years.

Keywords: Contractualization, educational management, school management

Resumen: El artículo, a partir de levantamiento de datos en fuentes primarias realizado en investigación interinstitucional que estudia estrategias de privatización en las redes estatales de enseñanza brasileñas, presenta y analiza la contractualización de la gestión educativa y escolar en los estados brasileños. Se constata que tras las experiencias pioneras de Minas Gerais otros estados introdujeron formas de contractualización de la gestión sobre todo en los últimos años.

Palabras clave: Contractualización, gestión educativa, gestión escolar. 


\section{INTRODUÇÃO}

Este artigo resulta de levantamento de dados no contexto da pesquisa interinstitucional, (GARCIA, ADRIÃO 2018) na qual se caracterizam e analisam dimensões da privatização em redes estaduais de ensino brasileiras e do Distrito Federal para a década compreendida entre os anos 2005 e 2015. A década selecionada abarca os dez primeiros anos de implementação da Lei de Responsabilidade Fiscal (LRF), considerando-se o prazo limite para a adaptação dos entes federados à nova legislação, Lei 101, de 4 de maio de 2000. (BRASIL, 2000)

A pesquisa mapeou a presença do setor privado nas redes estaduais e Distrito Federal em três dimensões: do currículo, da oferta e gestão educacional, e escolar. A primeira dimensão se refere às atividades fins escolares; a segunda aos subsídios públicos ao setor privado para oferta de vagas. Finalmente, gestão educacional e gestão escolar são abordadas tanto da perspectiva de implementação de programas e ações por agentes privados, com e sem fins lucrativos, quanto pela adoção por parte do gestor público de medidas gerenciais típicas do mercado (GARCIA, ADRIÃO, 2018)

O artigo debruça-se sobre esta última perspectiva: a administração gerencial, com foco na introdução de um instrumento específico de gestão: a contratualização de resultados.

A partir dos anos 1990, o Estado brasileiro passa por reformas, sobretudo após a eleição de Fernando Henrique Cardoso em 1995, quando é produzido Plano Diretor de Reforma do Aparelho do Estado - PDRAE (PERONI 2013; PERONI, OLIVEIRA; FERNANDES, 2009), que, segundo Bresser-Pereira, ministro a frente do Ministério de Reforma do Aparelho de Estado (MARE), faziase necessária devido a "uma crise fiscal do Estado (BRESSER- PEREIRA, 1998, p. 23). A orientação implicava a busca de superação da burocracia, tendo em vista a modernização da gestão pública, adotando-se os referenciais da Administração Gerencial, ou Nova Gestão Pública (BRESSER- PEREIRA, 1998, BRESSERPEREIRA; SPINK, 1998). Altera-se a noção de propriedade, instituindo-se a ideia do público não estatal; instrumentos próprios à gestão privada também passaram a ser adotados como ferramentas para assegurar qualidade no setor público e atendimento eficiente ao cidadão consumidor (BRASIL, 1995).

A adoção da administração gerencial expressa como intencionalidade pelo PDRAE manteve-se como diretriz nas últimas duas décadas, aprofundandose a política de aproximação com o setor privado e introdução de mecanismos legais para compartilhamento da gestão de políticas sociais com a sociedade civil. (ADRIÃO, PINHEIRO, 2012) 
A despeito da propagada crise fiscal, entende-se que as reformas nos estados nacionais, a partir das últimas décadas do século $\mathrm{XX}$, respondem à crise econômica vivida nos anos 1970 (PERONI, 2010, GARCIA; ADRIÃO; BORGHI, 2009, ADRIÃO, 2009, entre outros). Destaca-se o pioneirismo do Reino Unido sob o comando de Margareth Thatcher, que adotou o neoliberalismo e o livre mercado como solução para os problemas fiscais. O radicalismo conservador das reformas neoliberais, todavia, em função das evidências de incapacidade de se manterem as estratégias políticas, deu lugar a respostas que supostamente envolveriam a sociedade civil na solução dos problemas econômicos e sociais. Sem rupturas profundas com a orientação neoliberal, nos anos 1990, a chamada Terceira Via introduz o terceiro setor como protagonista nas políticas sociais, sem, no entanto, romper com o diagnóstico neoliberal. (ROBERTSON, VERGER, 2012). Concordando ainda com Vera Peroni:

Existe uma crise estrutural do capital e o neoliberalismo, a globalização, a
reestruturação produtiva e a terceira via são estratégias do capital para a superação
de sua crise de diminuição na taxa de lucro e são essas estratégias que redefinem
o papel do Estado. Assim, a crise no Estado seria consequência e não causa. A
globalização, principalmente a financeira, mas também a produtiva, com as
mudanças nos mercados mundiais, redefine o papel do Estado. A reestruturação
produtiva também, pois alterou em muito os postos de trabalho e as concepções de
gestão. (PERONI, 2013, p.237)

No Brasil, as parcerias com o setor privado receberam suporte legal para se constituir a partir da aprovação da Lei Federal no 9.790, de 1999 (BRASIL, 1999a) e o Decreto 3.100, também de 1999 (BRASIL, 1999b), que regulamentaram as Organizações da Sociedade Civil de Interesse Público (OSCIP). (ADRIÃO, et al, 2012)

A Lei de Responsabilidade Fiscal- Lei Complementar no 101, de 2000 (BRASIL, 2000) por sua vez, contribuiu para acelerar a busca de parceiros privados, pois ao limitar os gastos orçamentários com pessoal em $60 \%$ dos recursos previstos, induziu o gestor público a buscar no setor privado soluções para prestação de serviços. (ADRIÃO, et al, 2009).

Em março de 2017, o Executivo Nacional sancionou a Lei 13.429 (BRASIL, 2017) que regulamenta o Projeto de Lei 4.302/1998 (BRASIL, 1998b), “alterando dispositivos da Lei no 6.019, de 1974 (BRASIL, 1974), que trata do trabalho temporário em empresas urbanas e dispõe sobre as relações de trabalho nas empresas de prestação de serviços a terceiros.” (DIEESE, 2017, p.2). Em que pese haver algumas dúvidas sobre as possibilidades criadas pela legislação para o setor público, em Nota Técnica o Dieese informa entendimento de que a legislação não deixa claro se as regras se aplicam ou não ao setor público (Ibidem)), 
o que no mínimo permite a hipótese de que as atividades escolares, incluindo as atividades-fim, possam ser transferidas ao setor privado com fins lucrativos.

Entende-se, todavia, para efeito da análise realizada neste trabalho, que processos de privatização da educação implicam não somente a transferência da propriedade, mas a transferência de serviços e responsabilidades do poder público para o setor privado, materializando-se também na adoção de processos tipicamente privados de gestão e organização do trabalho no interior da administração pública. Stephen J. Ball e Deborah Youdell (2008) consideram a transferência para o setor privado como privatização exógena e a adoção da lógica privada no interior do poder público como privatização endógena.

Licínio Lima (2013) também destaca que a privatização, além da "erosão de responsabilidades estatais em benefício de privados", pode ainda significar a adoção do que denomina como "cânone gerencialista". Nas palavras do autor, a privatização:

Pode, ainda, significar a crescente introdução de modos de gestão considerados típicos das organizações privadas, ideologicamente consideradas mais bem geridas, em busca da "zero-burocracia", mais ágeis e manejáveis em ambientes incertos e turbulentos, centradas na necessidade do cliente ou consumidor, induzindo a competitividade no seu interior através da adoção de mercados internos, ou seja, seguindo os princípios normativos e as prescrições técnico-instrumentais da chamada "Nova Gestão Pública", que tenho associado ao que designo por "cânone gerencialista” (LIMA, 2013, p.178-9)

Pesquisas realizadas em contexto brasileiro (CAMINI, 2009, NETO; CASTRO, 2011, PERONI, 2013, entre outros) indicam que no mais das vezes, a transferência de serviços e responsabilidades educacionais para o setor privado, com ou sem fins lucrativos, é acompanhada de adoção, por parte do gestor público, do modelo administrativo gerencial, ou pelo menos de instrumentos gerenciais de gestão associados à Nova Gestão Pública.

Nas palavras de Dave Hill, há um Plano de Negócios do capitalismo para a educação que contribui para construir agenda de acordo com os interesses dos mercados educacionais, com a importação do modo de gestão do capital privado: 
O "New Public Managerialism" - a importação para dentro dos velhos serviços públicos do estilo, linguajar e do modo de gestão do capital privado - substituiu a ética, linguagem, estilo e dever destes serviços públicos. A educação como uma instituição social está subordinada às metas do mercado internacional que incluem a linguagem e a autoconcepção dos próprios educadores (veja MULDERRIG, 2002, 2003; LEVIDOW, 2002). Mulderrig (na atual edição deste periódico) mostra como a educação está teoricamente posicionada em termos de sua relação com a economia e com as políticas do Estado em geral (aonde) uma racionalidade instrumental fundamenta os discursos de políticas educacionais, que se manifestam dentro de uma retórica influente e de valores de mercado em representações da educação pelos representantes e em sua prática” (HILL, 2003, p. 33)

No contexto da importação do modo de gestão privada, concentrase, neste trabalho, a atenção no instrumento contratual. A partir da análise do acordo de resultados mineiro, objeto inicial de estudo, verificou-se que outras redes públicas adotaram os contratos de gestão ou acordos de resultados. Buscase proceder à caracterização do instrumento, realizando-se inferências com a hipótese de ser a contratualização uma tendência na administração pública nos últimos anos, com decorrências para a gestão escolar e mais uma forma de aproximação entre o poder público e representantes do setor privado.

Realizou-se levantamento de informações nas páginas oficiais das secretarias de estado da educação e em documentos legais. Buscou-se também a legislação que implanta os acordos/contratos. Exclusivamente para produção deste trabalho, extrapolou-se a década considerada no escopo da pesquisa originária do estudo, a fim de serem abarcados documentos produzidos após o penúltimo processo eleitoral para governadores de estado que ocorreu em 2014, com posse em 2015.

Os documentos localizados foram produzidos no contexto de reformas no âmbito da administração pública, com foco na gestão por resultados. As especificidades dizem respeito às autonomias, premiações, formas de negociação, mas com pontos em comum, sobretudo o foco no desempenho.

A literatura informa que o pioneirismo na implementação de reformas com contratualização de resultados coube ao estado de Minas Gerais, que já tinha vivenciado reformas anteriormente, inclusive no campo educacional. (OLIVEIRA; DUARTE, 1997, QUEIROZ, 2009, TRIPODI, 2012 entre outros)

O artigo é organizado em três itens além desta introdução: a seguir, é feita breve incursão sobre o tema contratualização de resultados na gestão pública; na sequência apresentam-se os dados sobre as redes estaduais, destacando-se inicialmente o pioneirismo de Minas Gerais. Ao final, como último item, esboçamse algumas considerações sobre o tema. 


\section{GESTÃO EDUCACIONAL E CONTRATUALIZAÇÃO DE RESULTADOS}

A contratualização na gestão pública foi introduzida na constituição brasileira pela Emenda Constitucional n¹9 de 1998 (BRASIL, 1998), que, entre outras mudanças, alterou o artigo constitucional de número 37, ao introduzir o parágrafo $8^{\circ}$, possibilitando o firmamento de contratos no âmbito da administração direta e indireta com vistas à fixação de metas por desempenho:

\footnotetext{
$\int 8^{\circ}$ A autonomia gerencial, orçamentária e financeira dos órgãos e entidades da administração direta e indireta poderá ser ampliada mediante contrato, a ser firmado entre seus administradores e o poder público, que tenha por objeto a fixação de metas de desempenho para o órgão ou entidade, cabendo à lei dispor sobre: [...] I - o prazo de duração do contrato; [...] II - os controles e critérios de avaliação de desempenho, direitos, obrigações e responsabilidade dos dirigentes; [...] III - a remuneração do pessoal. (BRASIL, 1998)
}

Ricardo Carneiro e Lúcio Otávio Seixas Barbosa, ao analisarem os contratos de gestão denominados acordos de resultados no estado de Minas Gerais, observam que a contratualização na gestão pública ainda é tema recente, embora seu surgimento date da década de 1960 na França. Segundo os autores, o tema "somente ganhou maior saliência nas duas últimas décadas, no âmbito do movimento reformista associado à Nova Gestão Pública. (CARNEIRO; BARBOSA, 2007, p.2)

No Brasil, a Emenda Constitucional nº 19 de 1998 é bem melhor entendida quando se trata de estabelecimento de relações entre o setor público e representantes do setor privado ou administração indireta. No âmbito da contratualização entre esferas da administração direta, há polêmica em relação à verdadeira natureza dos acordos firmados. Zélia Di Pietro, por exemplo, compreende que na administração direta não se encontram presentes as características que levariam ao firmamento de um contrato, pois não há personalidades jurídicas distintas. $\mathrm{Na}$ administração direta, "contratante" e "contratado" representam a mesma pessoa jurídica. Diznos a autora:

Esses contratos correspondem, na realidade, quando muito, a termos de compromissos assumidos por dirigentes de órgãos, para lograrem maior autonomia e se obrigarem a cumprir metas. Além disso, correspondem àquelas que estão obrigadas a cumprir por força da própria lei que define as atribuições do órgão público; a outorga de maior autonomia é um incentivo ou um instrumento que facilita a consecução das metas legais. (DI PIETRO, 2002, p. 290) 
Na década de 1990, a mesma autora observara que no direito francês o contrato de gestão já fora previsto no âmbito da administração direta. A designação 'contrato' para a relação estabelecida na administração direta ocorria, em sua análise, por falta de termo melhor, pois não se tratava de verdadeiros contratos. (DI PIETRO, 1996).

Os documentos examinados neste artigo, embora não se tratem de contratos entre distintas personalidades jurídicas, estabelecem distribuição de responsabilidades entre as partes, cabendo aos gestores a responsabilidade pelo alcance de metas a serem atingidas pelas unidades escolares e pela Secretaria de Educação; explicitam instrumentos de monitoramento e controle; e introduzem autonomias financeiras e orçamentárias, além de formas diversas de premiação e sanções.

Destaca-se que as medidas de contratualização são integradas às proposições de gestão por resultados, uma das principais orientações da Nova Gestão Pública (GOMES,2009). Catarina Segatto e Fernando Abrúcio registram ser a partir dos anos 1990 no Brasil que mecanismos de gestão por resultados passam as ser adotados com maior intensidade. Para os autores, as avaliações foram os primeiros instrumentos. " $\mathrm{E}$, assim como na experiência internacional, foram adotados mecanismos de incentivo, premiação e sanção.” (SEGATTO; ABRÚCIO, 2017, p.87)

Os autores, estudando quatro casos de reformas educacionais em quatro estados brasileiros até o ano de 2010, identificaram que, no âmbito da gestão por resultados, há recurso a instrumentos diferenciados em sua implementação (SEGATTO, ABRÚCIO, 2017) implicando ou não a contratualização formal com gestores educacionais. De toda forma, as marcas das reformas são: foco nos resultados; responsabilização ou accountability; produção de mecanismos de monitoramento; introdução de indicadores de desempenho; avaliação em larga escala; e bonificação. (SEGATTO, ABRÚCIO, 2017)

Os instrumentos de contratualização, pode-se inferir, configuram-se em medidas específicas na introdução de reformas com foco em resultados. Como veremos na sequência, há também em relação aos contratos diferentes possibilidades de organização. 


\section{ACORDOS DE RESULTADO, CONTRATOS DE GESTÃO, TERMOS DE COMPROMISSO E PACTUAÇÃO: O PIONEIRISMO DE MINAS GERAIS E A CONTRATUALIZAÇÃO EM OUTRAS REDES ESTADUAIS DE ENSINO}

Neste item apresentam-se dados obtidos por meio de consulta a fontes primárias de pesquisa. Todavia, em relação ao estado de Minas Gerais, devido a seu pioneirismo e à significativa produção de análises, recorre-se também a fontes secundárias. Observa-se a nomenclatura diferenciada nas legislações locais. São utilizados termos como "Acordo de Resultados" "Termos de Compromisso" e mesmo "Contrato de Gestão".

O Acordo de Resultados em Minas Gerais foi introduzido no contexto da reforma administrativa denominada "Programa Choque de Gestão", implementada pelo governador Aécio Neves, do Partido da Social Democracia, no ano de 2003. ${ }^{1}$ (QUEIROZ, 2009)

Maria do Rosário Tripodi, ao analisar a implementação do Acordo de Resultados mineiro observa que a permanência na orientação ideológica da política pública mineira teria favorecido a "implementação do modelo de Estado Contratual como forma de regulação do sistema educacional, com todos os seus desdobramentos" (TRIPODI, M.R. F., 2012, p. 38). A mesma autora assim sintetiza os objetivos declarados do Programa: "imprimir modernidade, transparência, agilidade e eficiência na gestão, adequando-a aos novos tempos" (Idem, p. 39).

Os Acordos de Resultados foram introduzidos como parte do Programa Choque de Gestão pela Lei 14.694, de 30 de julho de 2003, prevendo políticas de bonificação por produtividade para os servidores públicos. A Lei disciplinava a avaliação de desempenho, Acordo de Resultados, autonomias gerencial, orçamentária e financeira e a aplicação de recursos (MINAS GERAIS, 2003).

O disciplinamento do Acordo foi dado pela Lei 17.600 de 2008, juntamente com os prêmios por produtividade atribuídos a partir do alcance de metas acordadas para as secretarias e, no caso da educação, também para as unidades escolares. A Lei definia o significado de acordo:

$1 \quad$ O "Choque de Gestão" perdurou por três mandatos governamentais, entre 2003 e 2014: sua implantação se deu no primeiro mandato de Aécio Neves (PSDB) que foi reeleito para o mandato subsequente (2007-2010). No ano de 2010, Aécio Neves renuncia ao governo do estado para concorrer ao Senado e assume o vice-governador, candidato eleito no pleito seguinte, Antonio Anastasia (PSDB). Anastasia também renuncia em 2014 para atuar na campanha presidencial do senador Aécio Neves. O Estado passa a ser governado pelo até então vice-governador Alberto Pinto Coelho Jr.(PP). A partir de $1^{\circ}$ de janeiro de 2015 toma posse o novo governador eleito, Aluizio Pimentel (PT), encerrando-se o ciclo. 
I - Acordo de Resultados: o instrumento de contratualização de resultados celebrado entre dirigentes de órgãos e entidades do Poder Executivo e as autoridades que sobre eles tenham poder hierárquico ou de supervisão (MINAS GERAIS, 2008, $\left.\operatorname{artigo} 1^{\circ}\right)$.

A Lei 17.600 de 2008 regulamentava a concessão das autonomias orçamentárias, financeiras e administrativas para órgãos e unidades acordados (art.18). Também determinava a constituição de Comissão de Acompanhamento e Avaliação, com responsabilidade de proceder à avaliação institucional (art. 11, III) ao final do ciclo avaliatório. Do resultado desta avaliação dependia o pagamento do prêmio por produtividade (Artigo 23), ao qual só faziam jus os servidores que atuam em instâncias nas quais vigora o Acordo.

O primeiro Acordo de Resultados firmado entre a Secretaria de Educação e o governo do Estado foi em 2007 (TRIPODI, 2012, ARAÚJO, 2016), com renovações anuais. A partir do primeiro acordo, as renovações passaram a ocorrer em duas etapas: na primeira etapa, o gestor à frente da Pasta da Educação firmava o acordo, estabelecendo metas junto ao governador do Estado e na segunda etapa os superintendentes regionais de ensino assinavam o acordo com a secretaria de educação (TRIPODI, 2012). Também todas as escolas estaduais assinavam o compromisso de obter os índices de desempenho previstos pelo Sistema Mineiro de Avaliação da Educação Básica - SIMAVE/PROEB. (AUGUSTO, 2012).

Abelardo Bento Araújo, em pesquisa de doutoramento, entrevista docentes e gestores da rede estadual de Minas Gerais. Apesar da suposta autonomia legal, ocorre a determinação das práticas pedagógicas orientadas em torno das avaliações externas. A pressuposta autonomia, assim, não se expressava em sua plenitude no cotidiano das escolas, restringindo-se a benefícios de ordem financeira individual (ARAÚJO, 2016) ${ }^{2}$.

\section{A CONTRATUALIZAÇÃO DE RESULTADOS EM OUTRAS REDES ESTADUAIS DE ENSINO E NO DISTRITO FEDERAL}

Por meio de consulta às páginas oficiais das secretarias estaduais de educação e às legislações estaduais, obtiveram-se informações sobre a existência de acordos/contratos entre os governos dos estados e as secretarias de educação e, em alguns casos, entre as secretarias e o(a) diretor (a) eleito, como ocorre no Estado do Maranhão. Os descritores utilizados para proceder à seleção de informações foram: 'contrato de gestão', 'acordo de resultados', 'termo de

2 O governo mineiro não conseguiu manter o pagamento dos prêmios por produtividade nos anos de 2013, 2014 e 2015, gerando ações judiciais. Em 2016, a Lei Estadual n. ${ }^{\circ}$ 22.257/2016 extinguiu o prêmio. 
compromisso'. O levantamento de informações para este trabalho privilegiou a produção de legislação normalizadora dos contratos, buscando caracterizar seus principais conteúdos.

Inicialmente, convém observar que a tônica nas reformas administrativas estaduais, com o impulso do PNAGE, conforme já observado, é a modernização da Gestão Pública na perspectiva da Gestão por Resultados. Com ou sem contratos ou acordos de resultados, destacam-se dois aspectos importantes:

- a administração gerencial como modelo para a administração pública e introdução de instrumentos de gestão próprios ao mercado;

-a presença de representantes do setor privado como colaboradores das reformas. Este é o caso da organização não governamental Movimento Brasil Competitivo (MBC), que assim se apresenta:

Desde 2001, o Movimento Brasil Competitivo aproxima os setores público e privado, investe na cultura de governança, promove a gestão de excelência com o objetivo de ampliar a competividade nacional, o aumento da capacidade de investimento do Estado e a melhora dos serviços públicos essenciais oferecidos aos brasileiros (MBC, s. d.)

$\mathrm{O} M B C$, movimento que representa o setor empresarial, com os objetivos acima, apresenta-se como aliado de vários governos estaduais. Uma das ações do grupo é voltada à constituição do "Pacto pela Reforma do Estado", que segundo a página oficial da OSCIP "representa a coalização público-privada que tem a missão de propor uma agenda de transformações compartilhadas entre União e estados". (MBC, s. d.) O MBC anuncia que participam do Pacto 19 estados e o Distrito Federal. Em outra iniciativa, o Programa Mais Gestão Pública, o MBC oferece soluções e apoio técnico para reformas administrativas, revisões de planos plurianuais de governo, criação de núcleos de assessoramento público-privado, redução de gastos e aumento de receitas, governança para resultados.

No estado do Mato Grosso do Sul (2015-2016), o MBC indica apoio na implantação do Acordo de Resultados. Em quatro estados da federação, o Movimento declara ter atuação na educação pública estadual: em Rondônia (2011), na modernização da gestão educacional; em Pernambuco (entre 2007 e 2015, atuou na melhoria dos indicadores educacionais, assim como no estado da Bahia (2008-2010) e no Rio de Janeiro, apoiou a implantação de software para 
sistematização do programa de remuneração variável. O MBC também declara ter oferecido solução ao Distrito Federal (2007-2009) para redução de gastos

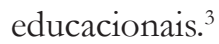

O setor privado com fins lucrativos também se beneficia das reformas gerenciais do que é exemplo a atuação da Consultoria Falconi. Na área pública, a consultoria oferece seus serviços no que denomina como "quatro iniciativas": equilíbrio fiscal; educação; segurança; e saúde. (FALCONI, s. d.). A consultoria declara ter como diferenciais no campo educacional o desenvolvimento da cultura de resultados; expertise em gestão; aprendizagem pelo fazer; e compromisso como $\mathrm{o}$ alcance de metas. Anuncia o desenvolvimento de projetos junto às secretarias estaduais de educação de Rondônia (2013-2014); Pará (2016); Ceará (2001-2007); Pernambuco (2007-2010); Sergipe (2005-2006); Bahia (2009); Rio de Janeiro (20102012) e São Paulo (2008 e 2016). As atividades desenvolvidas citadas na página oficial da consultoria são: reestruturação da secretaria de educação (Rondônia); implementação de modelos de gestão por resultados em unidades escolares (São Paulo; Ceará; Pernambuco, Bahia, Rio de Janeiro); definição de metas globais, desdobradas para as unidades escolares; e desenvolvimento de instrumentos de acompanhamento com vistas a elevação do IDEB (Pará, Pernambuco, Bahia); elevação das taxas de aprovação (Sergipe). (FALCONI, EDUCAÇÃO. s.d.).

A adoção de modelos privados de gestão pela administração pública e a presença de representantes do setor privado indica, considerados os exemplos acima e a literatura produzida na área, caráter crescente. Observemos agora os estados nos quais a gestão educacional foi contratualizada.

Destaca-, inicialmente, que todos os acordos localizados são posteriores ao "Choque de Gestão" mineiro. Neste levantamento inicial, foram identificados11 estados e o Distrito Federal com legislações normalizando a contratualização. Foram pesquisados para este artigo exclusivamente os textos legais, buscandose compreender: os termos de contratualização; os envolvidos; objetos de contratualização; objetivos. Embora em vários estados a contratualização tenha sido regulamentada posteriormente à sua lei de criação (caso de Minas Gerais), optou-se por indicar a primeira legislação encontrada, a fim de se registrar o início de adoção da política. O quadro 1 sintetiza as informações.

3

. O MBC foi fundado em 2001, quando a presidência do Conselho Superior do MBC coube a Jorge Gerdau Johannpeter, presidente do conselho de administração do grupo Gerdau. Desde então, o Movimento atua em parceria com o poder público. Entre os associados mantenedores, encontram-se empresas como Grupo Globo, Google, Intel, Odrebrecht, Gerdau, Souza Cruz, Suzano, Fiat, CFL Energia, Itaipu Binacional, Itaú, entre outros. (MBC.Histórico, s. d.). 
Quadro1: Entes federados, contratualização de resultados na administração direta (educação), termo utilizado, legislação e partidos no governo no ano da implementação do texto legal

\begin{tabular}{|c|c|c|c|c|c|}
\hline Estado & $\begin{array}{l}\text { Termo para a } \\
\text { contratualização } \\
\text { de resultados }\end{array}$ & Lei/Decreto & ano & $\begin{array}{l}\text { Secretaria de } \\
\text { Educação }\end{array}$ & $\begin{array}{c}\text { Partido no } \\
\text { governo na } \\
\text { implantação }\end{array}$ \\
\hline Ceará & $\begin{array}{l}\text { Acordo de } \\
\text { resultados }\end{array}$ & Lei 13.875 & 2007 & Sim & PSDB \\
\hline Distrito Federal & $\begin{array}{l}\text { Acordo de } \\
\text { Resultados }\end{array}$ & Decreto 37.573 & 2016 & Sim & PSB \\
\hline Goiás & $\begin{array}{l}\text { Acordo de } \\
\text { Resultados }\end{array}$ & $\begin{array}{l}\text { Decreto } n^{0} \\
8.170\end{array}$ & 2014 & Sim & PSDB \\
\hline Maranhão & $\begin{array}{l}\text { Contrato de } \\
\text { Gestão }\end{array}$ & Lei 9.965 & 2011 & Sim & PMDB \\
\hline Mato Grosso & $\begin{array}{l}\text { Acordo de } \\
\text { Resultados }\end{array}$ & Decreto 16 & 2015 & Sim & PSDB \\
\hline $\begin{array}{l}\text { Mato Grosso } \\
\text { do Sul }\end{array}$ & $\begin{array}{l}\text { Contrato de } \\
\text { Gestão }\end{array}$ & Lei 4640 & 2014 & Sim & PSDB \\
\hline Minas Gerais & $\begin{array}{l}\text { Acordo de } \\
\text { Resultados }\end{array}$ & Lei 14.694 & 2003 & Sim & PSDB \\
\hline Pará & $\begin{array}{l}\text { Acordo de } \\
\text { Resultados }\end{array}$ & Decreto 352 & 2012 & Sim & PSDB \\
\hline Paraná & $\begin{array}{l}\text { Acordo de } \\
\text { Resultados }\end{array}$ & Decreto 3505 & 2011 & Sim & PSDB \\
\hline Pernambuco & $\begin{array}{c}\text { Pacto de } \\
\text { Resultados do } \\
\text { gestor escolar }\end{array}$ & Decreto 39.336 & 2013 & Sim & PSB \\
\hline $\begin{array}{l}\text { Rio Grande do. } \\
\text { Norte }\end{array}$ & $\begin{array}{l}\text { Contrato de } \\
\text { Gestão }\end{array}$ & 26.090 & 2016 & Sim & PSD \\
\hline $\begin{array}{l}\text { Rio Grande } \\
\text { do Sul }\end{array}$ & $\begin{array}{l}\text { Contrato de } \\
\text { Gestão }\end{array}$ & Lei 12.237 & 2005 & Sim & PMDB \\
\hline Tocantins & $\begin{array}{l}\text { Compromisso por } \\
\text { resultados }\end{array}$ & Lei 2.663 & 2012 & Sim & PSDB \\
\hline
\end{tabular}

Os estados constantes do quadro 1, com os descritores selecionados, foram os entes federados para os quais se localizaram legislações sobre a contratualização. Balanço dos documentos legais pesquisados permite considerar um padrão nos conteúdos dos termos contratualidades, conforme síntese a seguir:

a) Metas estabelecidas com base em avaliações de larga escala, com perspectivas de elevação dos índices de rendimento;

b) Presença de metas relacionadas à economia de recursos materiais;

c) Perspectivas de premiação por produtividade (desempenho dos estudantes) e assiduidade do profissional; 
d) Concessão de autonomias administrativas orçamentárias no âmbito das secretarias de educação, envolvendo a possibilidade de estabelecimento de convênios, mobilização de pessoal e, em alguns casos, também no âmbito das unidades escolares;

e) Criação de comissões ou comitês de fiscalização e controle sobre os termos do acordo;

f) Possibilidade de rescisão do acordo a qualquer momento por parte do acordante;

g) Gestores escolares são os responsáveis nas unidades de ensino pelo alcance das metas que cabem à escola e se encontram estabelecidas no contrato/ acordo;

Em alguns casos, os gestores assinam os termos do contrato, responsabilizando-se pelo alcance das metas firmadas frente ao governo do estado. No caso do estado do Maranhão, as medidas anunciadas na legislação são rigorosas para o não cumprimento de metas estabelecidas: o governo do estado, em Decreto que regulamentou a escolha dos diretores escolares no ano de 2015, estabelecia que a última etapa para contratação dos mesmos se constituiria por: 'Assinatura do contrato de gestão, visando ao cumprimento das diretrizes e planos governamentais que orientam o processo e estabelecem mecanismos de monitoramento e controle do desempenho gerencial." (DECRETO 30. 619, art. $2^{\circ}$, Inc. IV, 2015). O contrato de gestão estabeleceria as metas qualitativas e quantitativas para a unidade escolar (Art. 28) pelas quais se responsabilizava o diretor. $\mathrm{O}$ mesmo decreto previa a possibilidade de exoneração da função gestora por "decisão motivada do Governador do Estado ou diante do descumprimento imotivado das metas estipuladas no contrato de gestão. (Decreto 30. 619 Art. 29, 2015).

Em outros estados, as medidas e sanções se referem muito mais à perda das autonomias e não pagamento da bonificação para as equipes, ou seja, perda da premiação.

Em que pesem as possíveis peculiaridades na construção dos contratos em cada um dos entes federados, destacam-se as funções decorrentes da gestão por resultados. Os acordos/contratos funcionam, assim, como instrumentos para articular as formas de gestão, responsabilizando os gestores e profissionais no interior da escola pelo considerado sucesso da política educacional dos governos. 


\section{ALGUMAS CONSIDERAÇÕES}

Tripodi ( 2012), em seu estudo sobre o acordo de resultados em Minas Gerais, elencou três aspectos a serem observados criticamente quando se trata se considerar um legítimo processo de negociação que envolveria um contrato: o primeiro deles seria o estabelecimento de metas, ou seja, resultados fechados que limitam a autonomia concedida no processo e induzem a "enquadramentos" pedagógicos com vistas ao alcance das metas; o segundo aspecto seria a possibilidade sempre presente de cessação da autonomia; por fim, a autora destaca a perspectiva da rigidez contratual implicada no próprio processo que induz ao cumprimento de metas. Tal rigidez contaria a flexibilização, em tese, suposta na contratualização, na qual as partes negociam. (TRIPODI, 2012)

As considerações da autora contribuem para refletir sobre a possível tendência de controle do trabalho nas escolas por meio de contratualização de resultados. Os riscos de conformação do processo pedagógico a um esforço contínuo para cumprimento de metas "pactuadas" reduzem o próprio sentido do processo educativo como atualização histórico-cultural humana (PARO, 2012). Há que se considerar, entretanto, que não apenas a assinatura de contratos entre secretários de educação e governos ou envolvendo gestores escolares e demais profissionais na escola propicia essa redução. Conforme autores mencionados neste texto, a gestão por resultados e a remuneração por produtividade não dependem exclusivamente de contratualizações formais, como é o caso do estado de São Paulo (SEGATTO; ABRÚCIO, 2017). Tais medidas, ao instaurarem a competividade no interior das escolas e entre unidades e direcionarem as atenções exclusivamente para resultados mensuráveis, concorrem para a redução das práticas pedagógicas.

Os contratos, entretanto, parecem ser instrumentos que fortemente aproximam do setor privado a educação pública, quer por meio da linguagem, quer por meio da lógica adotada ou, ainda, pela própria participação do setor privado na configuração da política pública, tal como sugerem os dois exemplos de atores privados mencionados neste texto; com ou sem fins lucrativos imediatos, atuando na implementação da gestão por resultados em administrações públicas estaduais brasileiras, não apenas assessoram, mas fazem a política, penetrando na gestão escolar. 


\section{REFERÊNCIAS}

ADRIÃO, T.; GARCIA, T. ; BORGHI, R. ; BERTAGNA, R. ; MOEHLECKE, S. . Mapeamento das estratégias de privatização da Educação Básica no Brasil (2005-2015). 2018. (Relatório de pesquisa).

ADRIÃO, T.; PINHEIRO, D. A presença do setor privado na gestão da educação pública: refletindo sobre experiências Brasileiras. Educação e Políticas em Debate, v. 1, p. 55-67, 2012.

ADRIÃO, T. Indicações e Reflexões sobre as Relações entre Esferas Públicas e Privadas para a Oferta Educacional no Brasil. Políticas Educativas, v. 3, p. 1-1, 2009.

ADRIÃO, et alii. As parcerias entre prefeituras paulistas e o setor privado na política educacional: expressão de simbiose? Educação \& Sociedade; v. 33, p. 533-549, 2012

ADRIÃO, et al. Estratégias municipais para a oferta da Educação Básica: análise de parcerias Público-privado no estado de São Paulo. Relatório de Pesquisa. 2009. Disponível em. https://drive.google.com/file/d/0B4J-SJB_ XFGfZ2NzSjVRSlgyRUU/view. Acesso em 16 de dezembro de 2017.

ARAÚJO, B.A. Avaliação e controle do trabalho educativo: contradições entre meios e fins no monitoramento da qualidade da educação.2016, 285f. Tese (Doutorado em Educação) - Universidade de São Paulo. São Paulo.2016

AUGUSTO. M.H. Regulação educativa e trabalho docente em Minas Gerais: a obrigação de resultados. Educação e Pesquisa, São Paulo, v. 38, n. 03, p. 695709, jul./set. 2012.

BALL, S.; YODELL, D. Privatización encubierta en la educación pública, Internacional de la Educación. Bruxelas, 2008. Disponível em: https:// www.joanmayans.com/privatizacion_encubierta_de_la_educacion_publica.pdf Acesso em 14 de junho de 2018. 
BRASIL. Lei Complementar $\mathbf{n}^{\circ}$ 101, de 4 de maio de 2000. Estabelece normas de finanças públicas voltadas para a responsabilidade na gestão fiscal e dá outras providências. Diário Oficial da União. Brasília: Senado Federal, 2000. Disponível em:. http://www.planalto.gov.br/ccivil_03/LEIS/LCP/Lcp101.htm. Acesso em 19 de agosto de 2107. Acesso em: 14 de maio de 2018.

BRASIL. Emenda Constitucional n. 19, de 4 de junho de 1998. Modifica o regime e dispõe sobre princípios e normas da Administração Pública, servidores e agentes políticos, controle de despesas e finanças públicas e custeio de atividades a cargo do Distrito Federal, e dá outras providências. Diário Oficial da União, Brasília, p. 1, 5 jun. 1998a. http://www.planalto.gov.br/ccivil_03/Constituicao/ Emendas/Emc/emc19.htm. Acesso em: 13 de maio de 2018.

BRASIL. Constituição da República Federativa do Brasil. Diário Oficial da União, 5 out. 1988. Disponível em: http://www.planalto.gov.br/ccivil_03/ constituicao/constituicao.htm.Acesso em: 13 de maio de 2018.

BRASIL..Lei Federal no. 9790, de 23 de março de 1999. Dispõe sobre a qualificação de pessoas jurídicas de direito privado, sem fins lucrativos, como Organizações da Sociedade Civil de Interesse Público, institui e disciplina o Termo de Parceria, e dá outras providências. Disponível em: http://www.planalto.gov. br/ccivil_03/LEIS/L9790.htm. Acesso em 14 de fevereiro de 2018.

BRASIL.Projeto de Lei no. 4302, de 1998. Dispõe sobre as relações de trabalho na empresa de trabalho temporário e na empresa de prestação de serviços a terceiros, e dá outras providências. Disponivel em: https://www.camara.leg.br/ proposicoesWeb/fichadetramitacao?idProposicao=20794. Acesso em 14 de fevereiro de 2018.

BRASIL. Lei Federal $\mathbf{n}^{\mathbf{0}} \mathbf{. 6 0 1 9}$, de 3 de janeiro de 1974. Dispõe sobre o Trabalho Temporário nas Empresas Urbanas, e dá outras Providências. Disponível em: http://www.planalto.gov.br/ccivil_03/leis/L6019.htm. Acesso em 11 de fevereiro de 2018.

BRESSER PEREIRA, L.C.; SPINK, P.K. (Org). Reforma do Estado e administração pública gerencial. Rio de Janeiro: Fundação Getúlio Vargas, 1998. 
BRESSER-PEREIRA. Uma reforma gerencial da administração pública no Brasil. Revista do Serviço Público. Ano 49 Número 1 Jan-Mar, p. 5-42, 1998.

\section{CAMINI, L. A Gestão Educacional e a Relação entre Entes Federados na} Política Educacional do PDE/Plano de Metas e Compromisso Todos pela Educação. 2000.298f. Tese( Doutorado em Educação). Universidade Federal do Rio Grande do Sul, Porto Alegre, 2009.

CARNEIRO, R.; BARBOSA , L.O. Acordo de resultados: análise da experiência do governo mineiro. In: Anais do XXXI EANPAD, Rio de Janeiro, 2007. Disponível em : http://www.anpad.org.br/admin/pdf/APS-A914.pdf .Acesso em 28 de fevereiro de 2018

CEARÁ. LEI $\mathbf{N}^{\mathbf{0}} \mathbf{1 3 . 8 7 5}$, de 7 de fevereiro de 2007. Dispõe sobre o Modelo de Gestão do Poder Executivo, altera a estrutura da Administração Estadual, promove a extinção e criação de cargos de direção e assessoramento superior, e dá outras providências. Brasília: Diário Oficial da União, 2007. https://www. al.ce.gov.br/legislativo/legislacao5/leis2007/13875.htm. Acesso em 25 de maio de 2018.

DI PIETRO, M. Z. Direito Administrativo. 14ª ed. São Paulo: Atlas, 2002.

DI PIETTRO, M.Z. Contratos de Gestão. Contratualização do Controle Administrativo sobre a administração indireta e sobre as organizações sociais. Disponível em: http://www.pge.sp.gov.br/centrodeestudos/revistaspge/ revista2/artigo9.htm Acesso e 23 de abril de 2017.

DIEESE. Nota Técnica: Impactos da Lei 13.429/2017 (antigo PL 4.302/1998) para os trabalhadores; Contrato de trabalho temporário e terceirização. SP, n 175, 2017. Impresso. Disponível em ttps://www.dieese.org.br/notatecnica/2017/ notaTec175TerceirizacaoTrabalhoTemporario.pdf .Acesso em 20 de abril de 2017.

DISTRITO FEDERAL. Decreto $\mathbf{n}^{\circ}$ 37.573, de 25 de agosto de 2016. Institui o Modelo de Gestão para Resultados do Distrito Federal, o Sistema Gestão-DF, o Selo Projeto Prioritário, normatiza a Rede de Gestão e dá outras providências. Brasília, 2016. Disponível em: http://www.saude.df.gov.br/wp-conteudo/ uploads/2018/04/Decreto-37573-de-25_08_2016_Modelo-de-Gest\%C3\%A3opara-Resultados-do-Distrito-Fed eral...pdf.Acesso em 5 de julho de 2018. 
FALCONI. Educação. Disponível em. https://falconi.com/educacao/pt/. Acesso em 2 de julho de 2018.

FALCONI. Segmentos.Área Pública. Disponível em: https://www.falconi. com/segmentos/area-publica/. Acesso em 2 de setembro de 2018.

GARCIA, T.; ADRIAO, T. M. F. ; BORGHI, R. . A Nova Gestão Pública e o Contexto Brasileiro. In: Angela Maria Martins. (Org.). Instituições educacionais: políticas, gestão e práticas profissionais. $1^{\mathrm{a}}$ ed.Santos: Editora LeopoldianumUniversidade Católica de Santos, 2009, v. 1, p. 9-23.

GARCIA, T; ADRIÃO, T. (Org.). Currículo, gestão e oferta da educação básica brasileira: incidências de atores privados nos sistemas estaduais (20052015). Curitiba: Editora CRV, 2018.

GOIÁS. Decreto no 8.170, de 02 de junho de 2014. Regulamenta a Lei n 17.867, de 20 de dezembro de 2012, que institui o Modelo de Gestão para Resultados no âmbito do Poder Executivo e dá outras providências. Goiânia, Imprensa Oficial, 2014. Disponível em: http://www.gabinetecivil.goias.gov.br/decretos/ numerados/2014/decreto_8170.htm. Acesso em 6 de julho de 2018.

GOMES,E.G.M. Gestão por Resultados e Eficiência na Administração Pública: uma análise à luz da experiencia de Minas Gerais.Tese.[Doutorado em Administração Pública e Governo.2009.187f. Fundação Getúlio Vargas. São Paulo.2009. Disponível em: http://bibliotecadigital.fgv.br/dspace/bitstream/ handle/10438/4652/72050100745.pdf?sequence=1\&isAllowed $=y$ Acesso e, 10 de julho de 2018.

HILL, D. O Neoliberalismo Global, a Resistência e a Deformação da Educação. Currículo sem Fronteiras, v.3, n.2, pp.24-59, Jul/Dez 2003.

LEVIDOW, L MARKETIZING, Higher Education: Neo-liberal Strategies and Counter-Strategies. The Commoner,.3 January,2002. at: http://www. commoner.org.uk/ 03levidow.pdf 
LIMA, L. Apresentação da seção temática - Privatização da educação no contexto $\mathrm{da}(\mathrm{s})$ "Terceira(s) Via(s)": uma caracterização em análise. Currículo sem Fronteiras, v. 13, n. 2, p. 177-181, maio/ago. 2013.Disponível em: http://www. curriculosemfronteiras.org/vol13iss2articles/apresentacao.pdf. Acesso em em 28 de maio de 2018.

MARANHÃO. Decreto $\mathbf{n}^{\mathbf{0}} \mathbf{3 0 . 6 1 9}$, de 02 de janeiro de 2015. Dispõe sobre o processo seletivo democrático para a função de gestão escolar das unidades de ensino da rede pública. Disponível em http://www.stc.ma.gov.br/legisladocumento/?id=3778. Acesso em 14 de novembro de 2017.

MATO GROSSO DO SUL. Lei No 4640 DE 24/12/2014. Reorganiza a Estrutura Básica do Poder Executivo do Estado de Mato Grosso do Sul, e dá outras providências .Disponível em: http://www.spdo.ms.gov.br/diariodoe/ Index/Download/42078. Acesso em 20 de novembro de 2017.

MATO GROSSO. Decreto $\mathbf{n}^{\mathbf{0}} \mathbf{1 6}$, de 09 de fevereiro de 2015. Disciplina os processos de elaboração, execução, monitoramento e avaliação dos acordos de resultados firmados por órgãos e entidades da Administração Pública Estadual, e dá outras providências. Disponível em: http://www.seplan.mt.gov. br/documents/363424/3973442/Decreto+16-2015+Monitoramento+AR. pdf/872eff00-fc00-4e2a-8968-c4cc942b4fb9. Acesso em 14 de junho 2018.

MINAS GERAIS. Lei, 14.694, de 30 de julho de 2003.Disciplina a avaliação de desempenho institucional, o Acordo de Resultados, a autonomia gerencial, orçamentária e financeira, a aplicação de recursos orçamentários provenientes de economias com despesas correntes no âmbito do Poder Executivo e dá outras providências. Disponível em: http://www.fazenda.mg.gov.br/empresas/ legislacao_tributaria/leis/114694_2003.htm. Acesso em 10 de novembro de 2017.

MINAS GERAIS. Lei 17.600, de 1 de julho de 2008. Disciplina o acordo de resultados e o prêmio por produtividade no âmbito do poder executivo e dá outras providências. Disponível em: http://ipsm.mg.gov.br/arquivos/legislacoes/ legislacao/leis/lei_17600.pdf. Acesso em 10 de novembro de 2017.

MOVIMENTO BRASIL COMPETITIVO. Iniciativas. Disponível em:// http://www.mbc.org.br/portal/\# Acesso em 13 de maio dE 2018. 
MOVIMENTO BRASIL COMPETITIVO. Sobre movimento Brasil Competitivo. http://www.mbc.org.br/portal/sobre-o-mbc/ Acesso em 03 de julho de 2018.

MULDERRIG, J. Consuming education: a critical discourse analysis of social actors in New Labour's education policy. Journal for Critical Education Policy Studies, 1 (1).2003 www.jceps.com.*

NETO; A. C; CASTRO, A.M. D.A. Gestão escolar em instituições de ensino médio: entre a gestão democrática e a gerencial. Educ. Soc., Campinas, v. 32, n. 116, p. 745-770, Sept. 2011.

OLIVEIRA, D. A., DUARTE, M.R.T. Política e administração da educação: Um estudo de algumas reformas recentes implementadas no estado de Minas Gerais. Educação \& Sociedade, ano XVIII, nº 58, julho/97, p.123-141, 1997.

PARÁ. Decreto $\mathrm{n}^{\mathbf{0}}$ 352, de 23 de fevereiro de 2012.Dispõe sobre a institucionalização do modelo de gestão para resultados no âmbito do Poder Executivo Estadual. Disponível em: https://www.sistemas.pa.gov.br/sisleis/ legislacao/250 Acesso em 2 de julho de 2018.

PARANÁ. Decreto $\mathrm{n}^{\circ} 3505$, de 14 de dezembro de 2011.Disponível em: https://www.legislacao.pr.gov.br/legislacao/pesquisarAto.do?action=exibir\&cod Ato $=62739 \&$ codItemAto $=478664$ Acesso em 2 de julho de 2018.

PARO, V.H. Administração escolar: introdução crítica. 17 ed.São Paulo. Cortez Editora.2012.[edição revista e ampliada]

PERONI, V.M.V. As Relações entre o Público e o Privado nas Políticas Educacionais no Contexto da Terceira Via. Currículo sem Fronteiras, v. 13, p. 234-255, 2013. Disponível em: http://www.curriculosemfronteiras.org/ vol13iss2articles/peroni.pdf. Acesso em 4 de março de 2018.

PERONI, V. M. V. A democratização da educação em tempos de parcerias entre o público e o privado. Revista de Educação Pública - UFMT, v. 19, p. 215-227, 2010. 
PERONI, V.M.V.; OLIVEIRA, R. T. C.; FERNANDES, M. D. E. Estado e terceiro setor: as novas regulações entre o público e o privado na gestão da educação básica brasileira. Educação \& Sociedade (Impresso), v. 30, p. 761-778, 2009.

PLANO DIRETOR DA REFORMA DO APARELHO DO ESTADO. Brasília. Presidência da República, Câmara da Reforma do Estado, Ministério da Administração Federal e Reforma do Estado.1995. Disponível em: http:// www.biblioteca.presidencia.gov.br/publicacoes-oficiais/catalogo/fhc/planodiretor-da-reforma-do-aparelho-do-estado-1995.pdf. Acesso em 3 de março de 2018.

QUEIROZ, R.G.M. Choque de Gestão em Minas Gerais (2003-2010): um exemplo de inovação no setor público? 2009.244f. Dissertação(Mestrado em Ciências Econômicas ) - Universidade Federal de Minas Gerais. Belo Horizonte. 2009 .

RIO GRANDE DO NORTE. Decreto $\mathbf{n}^{\mathbf{0}}$ 26.090, de 17 de maio de 2016. Disciplina o Contrato de Gestão no âmbito do Poder Executivo e dá outras providências. Disponível em:// http://adcon.rn.gov.br/ACERVO/gac/DOC/ DOC00000000116865.PDF QAcesso em 14 de julho de 2018.

ROBERTSON, S., VERGER, A. A origem das parcerias público-privada na governança global da educação. Educ. Soc., Dez 2012, vol.33, n.121, p.11331156. ISSN 0101-7330, 2012. Disponívem em: http://www.scielo.br/scielo. php?script $=$ sci_abstract\&pid $=$ S0101-73302012000400012\&lng $=$ en\&nrm $=$ iso \& tlng=pt Acesso em : 01/06/2017.

SEGATTO, I.C, ABRÚCIO, F.A gestão por resultados em quatro estados brasileiros. Rev. Serv. Público. Brasilia, 68 (1). 85-106 jan/mar 2017.Disponível em: https://revista.enap.gov.br/index.php/RSP/article/view/762 Acesso em 23 de maio de 2018.

TRIPODI, M.R.F. O estado contratual e a nova agenda da educação: o caso de Minas Gerais. Revista @mbienteeducação. 5(1): 32-50, jan/jun, 2012 Disponível em: http://arquivos.cruzeirodosuleducacional.edu.br/principal/old/ revista_educacao/pdf/volme_5_1/educacao_01_32-50.pdf Acesso em 20 de maio. de 2018 
Sites

http://www.pge.sp.gov.br

https://falconi.com/educacao/pt

TEISE DE OLIVEIRA GUARANHA GARCIA é professora da Universidade de São Paulo-campus Ribeirão Preto , FFCLRP, Departamento de Educação, Informação e Comunicação e no Programa de Pós-Graduação em Educação da FFCLRP..Tem experiência na área de Educação, com ênfase em Administração Educacional e Administração de Unidades Educativas na Educação Básica, desenvolvendo pesquisas sobre a gestão educacional no contexto das relações entre o público e privado. E-mail: teise@ffclrp.usp.br

Recebido em setembro de 2018 Aprovado em fevereiro de 2019 